\title{
Bowel Evisceration Following Attempt at Umbilical Vein Catheterization in a Neonate: A Case Report
}

Chukwubuike Kevin Emeka

Pediatric Surgery Unit, Department of Surgery, Enugu State University Teaching Hospital, Enugu, Nigeria.

*Corresponding Author: Chukwubuike Kevin Emeka, Department of Surgery, Enugu State University Teaching Hospital, Enugu, Nigeria

Received date: September 25, 2021; Accepted date: October 5, 2021; published date; October 25, 2021

Citation: Chukwubuike Kevin Emeka (2021) Bowel Evisceration Following Attempt at Umbilical Vein Catheterization in a Neonate: A Case Report J, Surgical Case Reports and Images 4(8); DOI: 10.31579/2690-1897/097

Copyright: () 2021, Chukwubuike Kevin Emeka, This is an open access article distributed under the Creative Commons Attribution License, which permits unrestricted use, distribution, and reproduction in any medium, provided the original work is properly cited.
Abstract
Catheterization of the umbilical vein provides a quick vascular access in neonates. It is a relatively easy procedure routinely performed in neonatal intensive care units. However, this procedure may come with lots of complications. We report a rare complication of bowel evisceration from the umbilicus following an attempt to catheterize the umbilical vein. This complication may be prevented by meticulous dissection and avoidance of probing of the umbilical vein during umbilical vein catheterization.
Keywords: bowel evisceration, complications, neonate jaundice, umbilical catheterization

\section{Introduction}

Embryologically, the umbilical vein serves as a channel for the transfer of oxygenated and nutrient-rich blood from the placenta to the fetal heart [1]. In the postnatal period, the umbilical vein can be catheterized for the administration of intravenous fluids, blood and medications. Umbilical catheterization is an easy and routinely performed procedure in neonatal intensive care units. It provides a fast central venous access [2]. One of the most common indications for umbilical vein catheterization in neonates is for exchange blood transfusion in severely jaundiced babies [3]. However, umbilical catheterization is not without complications. Some of the complications include infection, air embolism, thromboembolic complications, pleural/ pericardial effusion, necrotizing enterocolitis and intestinal perforation [2]. Damage to the peritoneal membrane resulting in bowel evisceration is an uncommon complication and is rarely reported. We reported a case of bowel evisceration that occurred in a jaundiced neonate during an attempt at umbilical catheterization for an exchange blood transfusion. The rarity and unusual nature of this condition makes it worthwhile of being reported.

\section{Case summary}

A 15-day old male neonate presented to the neonatal unit of the hospital with a history of fever and jaundice of 12 days duration prior to presentation. The jaundice was of gradual onset and was progressively getting worse. Fever was high grade. The neonate was a product of term gestation, born by a 32-year old para-4 mother. Delivery was through a caesarian section and the indication for the caesarian section was prolonged labour with fetal distress. He cried spontaneously at birth, passed meconium within 24 hours of postnatal life and suckles the breast well. The baby was delivered in a peripheral hospital and was referred to Enugu State University Teaching Hospital (ESUTH) Enugu on account of fever and jaundice.

The mother booked for antenatal care at a gestational age of 15 weeks and there was no history of ingestion of herbal concoction in early pregnancy. She took routine antenatal drugs that contain iron and folic acid. The mother had a febrile illness at 23 weeks of gestation and was given an antimalarial (? name) at a health center. The mother had no skin rashes or foul smelling vaginal discharge during pregnancy and she is neither a known hypertensive nor a diabetic.

At the initial evaluation at ESUTH, he had a temperature of 37.9 degrees Centigrade, respiratory rate of 32 cycles per minute, heart rate of 160 beats per minute, occipitofrontal circumference (OFC) of 34 centimeter $(\mathrm{cm})$. His weight was 2.2 kilograms. He was severely jaundiced which showed in all parts of his body. A diagnosis of neonatal sepsis and jaundice was made.

Laboratory investigation showed a total serum bilirubin of $285 \mu \mathrm{mol}$ per liter with conjugated bilirubin fraction accounting for $21 \mu \mathrm{mol}$ per liter. Total white blood cell count was $15.1 \times 10^{9} / \mathrm{L}$ and hemoglobin level was 18 grams per deciliter. A decision was taken by the neonatologist to catheterize the umbilical vein for a possible exchange blood transfusion. On an attempt to catheterize the umbilical vein, the bowel eviscerated from the umbilicus (Figure 1). 


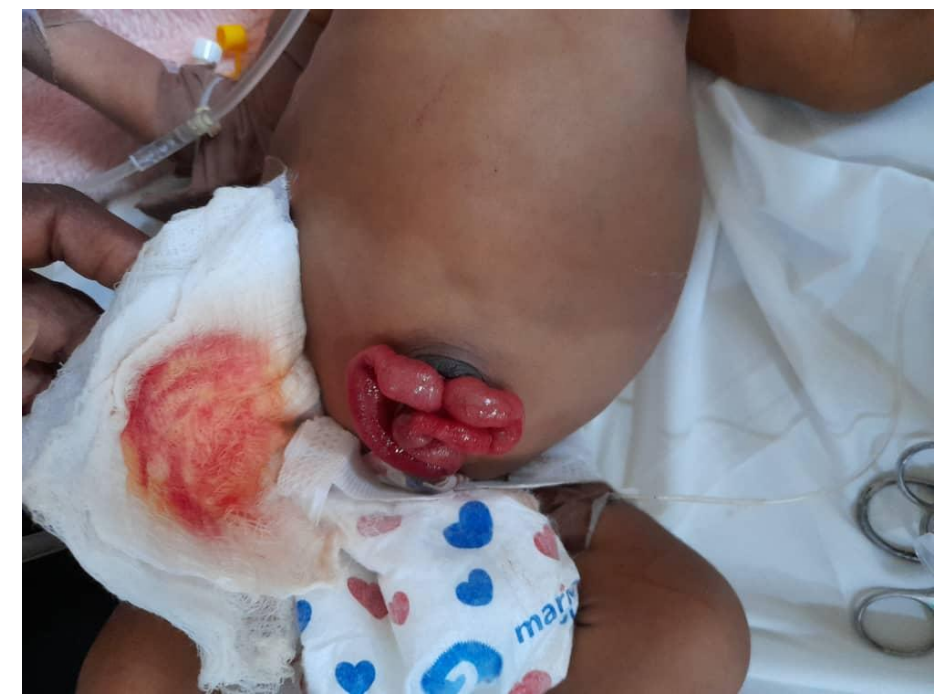

Figure 1: Bowel eviscerating from the umbilicus

The baby was optimized and taken to theatre. The bowel was found to be viable and there was no gut injury. The bowel was thoroughly cleaned with wet mop and was meticulously returned to the abdominal cavity without trauma to the gut. There was no further attempt to identify and cannulate the umbilical vein during the closure of the anterior abdominal wall. The defect in the umbilicus was about $4 \mathrm{~cm}$ and was closed using delayed absorbable sutures and an umbilicoplasty was also performed (Figure 2). The neonate achieved good healing and was discharged from pediatric surgery services on the fifth day post closure.

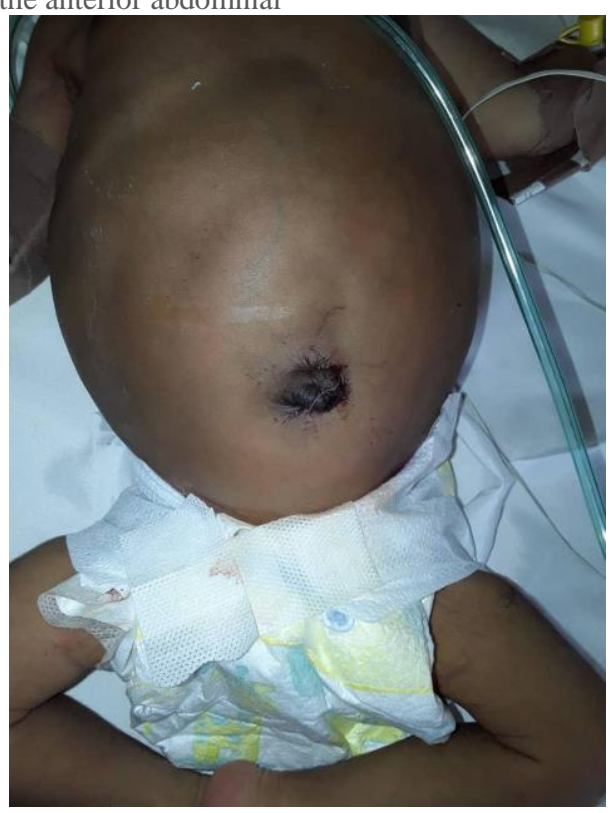

Figure 2: Appearance of the abdomen following closure

\section{Discussion}

Historically, in 1925 Hart described a technique of exchange transfusion by withdrawing jaundiced blood from the superior sagittal sinus and injecting fresh non-jaundiced blood into the saphenous vein [4]. However, this technique is obsolete and has long been abandoned. The current technique of direct umbilical vein catheterization, aimed at reducing difficulties and challenges of umbilical catheterization, was described by Sanchez et al [5]. In neonates with severe jaundice, exchange blood transfusion is an established and effective method of treatment in order to avoid kernicterus from hyperbilirubinemia.

The umbilical vein is one of the most frequently used vascular accesses in the first few days of life and in the neonatal intensive care units; cannulation of the umbilical vein is a common procedure [2]. No general anesthesia is required for umbilical vein cannulation. It is a simple and short procedure [6].

One study from Edo State Nigeria also reported intestinal evisceration through the umbilicus following an attempt at umbilical vein catheterization [3]. The author reported that the attempt at umbilical cannulation was difficult and an attempt was made to scrap and probe the umbilical region which may have caused the bowel evisceration [3]. Pathologies in the neonatal umbilical area may have also predisposed to bowel evisceration. Kittur et al reported the occurrence of bowel evisceration in a neonate with umbilical hernia [7]. In older neonates, umbilical vein catheterization may be associated with some difficulties and manipulations around the umbilical area may have weakened the 
attachment of the umbilical ring leading to evisceration [3]. Prematurity and low birth weight may also be other contributory factors [3].

\section{References}

1. Spurman J, Logan P, Pak S. (2012) The development, structure and blood flow within the umbilical cord with particular reference to the venous system. Australas J Ultrasound Med.; 15(3): 97-102.

2. Bothur-Nowacka J, (2011) Czech-Kowalska J, Gruszfeld D, Nowakowska-Rysz M, Kosciesza A et al. Complications of umbilical vein catheterization. Case Report. Pol J Radiol.; 76(3): 70-73

3. Eighemhenrio A. (2016) Evisceration of small bowel from umbilical vein catheterization in a preterm African neonate: An uncommon complication. East and Central African Journal of Surgery.; 21(1): 93-95

4. Hart AP. (1925) Familial Icterus Grains of the New-born and its Treatment. Can Med Assoc J.; 15(10): 1008-1011

5. Sanchez FR. (1960) A new approach to catheterization of the umbilical vein for exchange transfusion. Pediatrics.; 25(3): 485-489

6. https://pubmed.ncbi.nlm.nih.gov/28920027/ M, Thale V, (2011) Vilser C, Merkel N. Umbilical venous catheters-analysis of malpositioning over a 10-year period. Z Geburtshilfe Neonatol.; 215(1): 18-22

7. Kittur DH. Bhandarkar KP, Patil SV, Jadhav SS. (2017) Rupture of the Umbilical Hernia with Evisceration in a Newborn.-A Case Report. J Neonatal Surg.; 6(3): 67
This work is licensed under Creative Commons Attribution 4.0 License

To Submit Your Article Click Here: Submit Manuscript

DOI: $10.31579 / 2690-1897 / 097$
Ready to submit your research? Choose Auctores and benefit from:

$>$ fast, convenient online submission

$>$ rigorous peer review by experienced research in your field

$>$ rapid publication on acceptance

$>$ authors retain copyrights

$>$ unique DOI for all articles

$>$ immediate, unrestricted online access

At Auctores, research is always in progress.

Learn more https://auctoresonline.org/journals/journal-of-surgical-casereports-and-images 